\title{
Steps for Engaging Young Children in Research: International innovative methods
}

Johnson, V., Hart, R. and Colwell, J.

\author{
Dr. Vicky Johnson, University of Brighton, contact: Vicky.Johnson@brighton.ac.uk \\ Professor Roger Hart, City University of New York \\ Dr. Jennifer Colwell, University of Brighton and Lyceum Education
}

\begin{abstract}
A framework of six steps for engaging young children in research is presented in this chapter. This framework was built through collaboration with a team of international researchers funded by the Bernard van Leer Foundation (Johnson, Hart, \& Colwell, $2014 a$ and b). Relevant literature and theoretical underpinning is presented with discussion of how creative participatory approaches are relevant to understanding and interacting with children's geographies. The framework addresses key issues facing researchers wishing to engage young children in research processes and offers ways to overcome some of the challenges researchers may face. In order to illustrate the six steps, a selection of case studies which provide examples of how experts from a wide range of international contexts have worked with children are presented. These case studies have been selected to be of particular relevance to geographic field research with young children and have been developed and tested by experts from a wide range of international contexts.
\end{abstract}

\section{Introduction}

In this chapter the position is assumed that all children are active competent participants in society who have full human value in the present (Mayall, 2000). When this standpoint is taken, involving children in research activities and decisionmaking is both desirable and necessary, particularly from a human rights perspective. Yet, embarking upon research with children, particularly young children under the age of eight years, often presents challenges which may, at times, lead to children being excluded from research. The six steps to engaging children in research presented in this chapter support those seeking to include children in their research to move away from what Clarke (2005) refers to as using adult 'lenses' with which to see childhood to conduct research with rather than on children (Mayall, 2002). This may extend to include research by children (Robinson and Kellett, 2004), although this is less often the case with very young children. These steps are relevant to engaging children and young people of all ages in the research process, however the specific focus of this chapter is children aged five to eight years of age.

The six steps were developed in consultation with active researchers who have had experience of participatory research with children (see Johnson et al., 2014a and 2014b). The steps provide guidance for researchers covering issues such as, developing ethical protocols, recognizing the importance of relationships with participants, selecting appropriate methods and, being aware of context and the benefits and challenges this may pose in the researcher. Discussions of these steps are framed by theory from a number of fields including social psychology, human geography and childhood studies and methods which may be of particular benefit when researching children's lives are presented. Case examples are also included to demonstrate the use of these methods in practice. 
The Right for children to express their opinions about issues that affect their lives is specified in Article 12 of the UN Convention on the Rights of the Child (UNCRC, 1989). As this article filtered into practice there has been a growing awareness that children's perspectives need to be heard and acted on (for example see: Save the Children, 1995). Indeed many organizations including non-governmental organizations have been contributing to these broader debates over many years. This has led to a number of exemplar cases being developed about the 'how's and why's' of including children's voices in research (Boyden, 1997).

Conceptualization of children's participation has expanded to include consideration of other articles of the UNCRC, such as Article 15 on the right to freedom of association (for example see the Article 15 project www.crc15.org) and Article 5 that discusses the responsibilities of adults to children (Landsdown 2010). There has also been reconceptualization of how child rights are realized internationally, for example to include the recognition of the complexity of children's everyday lives and issues of social justice (Hanson and Nieuwenhuys 2013). Increasingly, research that seeks to understand this complexity and identify support/ interventions that improve children's lives, engages with children across the lifecourse as active participants and agents of change using a range of participatory approaches and methods.

The following chapter specifically focuses on those approaches that have successfully engaged young children. Evidence that provides insight into young children's' perceptions and seeks to understand their lives includes visual and narrative data about their everyday activities, responses, preferences, priorities and dreams. Such evidence can directly inform interventions or services, and also be offered to policy makers to demonstrate to them why children should be included research, and why children's evidence should be taken seriously in decision-making (see for example Mason and Fattore, 2005).

\section{Distinctions: How does research with young children differ?}

Researching children's perspectives on their lives and geographies through engaging with them as active participants requires researchers to be creative (Christensen and James 2008). For example, where more conventional interviews are not holding the attention of younger children, then creative games and prompts can be used in order to involve them. Visual and narrative approaches may hold the attention of both adults and children of all ages, but particular approaches may be developed to take into account the developing capacities of children with age (Hart, 1998). For example three-dimensional visual methods, such as using clay and models, can be successful with young children, as described later in the steps framework.

There are particular ethical issues that need to be considered in order for research to be in the best interest of the children, whether they are treated as active participants or as subjects in the research process (Punch, 2015). The steps framework presented later in this chapter therefore prioritises not only the range of engaging methods that can be used with young children, but also the importance of: considering capacities and capabilities of researchers; developing ethical protocols and procedures; and building trust and relationships with the young children. Power relationships within the research process should also be considered. Mayall (2002) suggests that inevitable power relationships between adult or even older child researchers and child participants can't be ignored and discusses how researchers need to be aware of taking the 'least adult role'. Intergenerational relationships both 
in children's lives and in research situations need to be understood and taken into account in planning, conducting and analysing research (Alanen and Mayall, 2001).

\section{Consequences: what happens when children's voices are not heard?}

While the idea of children expressing their opinions has been recognized in international agreements as an integral part of realizing children's rights, in practice children's perspectives have still often been ignored or sidelined in research. One such example is the area of international development interventions (Bourdillon, 2004, Bartlett, 2005). Johnson (2010a), for example, noted that children were not consulted in the development of a water program in Nepal in 2000/2001. This resulted in the water taps being built too high for the children to access them safely. This was particularly problematic as the children held the responsibility for collecting water within households. In order to reach the taps they had to precariously swing off them. Involving children in the research and consultation process could have avoided the children being exposed to this danger. By later engaging children in an impact assessment of the project steps were built so children could reach the taps safely.

In this same research Johnson (2010a) observed additional cases where the inclusion of children in the research and evaluation process would have been beneficial to development interventions. For example, an income-generating program for women in rural areas was initially deemed a success, however children were not involved in the evaluation process. Further scrutiny revealed that the project had an unanticipated impact on children's lives. As the adults' daily routine changed due to the program and they were no longer available to tend the livestock as they became involved in work outside of the family the children in the village bore the responsibility of this role and as a consequence their attendance at school dropped. Impacting negatively on the children's educational opportunities.

Such examples highlight the practical value of involving children in the research process. They demonstrate how children's experiences need to be considered and taken seriously in both planning and evaluation processes for development programs to lead to the successful outcomes for which they strive; since children are active members and contributors to their families and communities (Evans, 2010).

\section{Challenges: why children may be excluded from research processes}

Whilst such examples highlight the need to include children in research, evidence suggests that children's voices are not always respected, that their reliability is questioned and that concerns over the extensive time required to develop ethical processes may lead to children being excluded. Indeed, where children are included in the research process their involvement does not necessarily lead to their voices being listened to or acted upon (Chawla and Johnson, 2004). There are many examples from both the global North and South that demonstrate the lack of attention given to children's views in understanding their 'lifeworlds' (for example see Nieuwenhuys 2005). Often power dynamics are such that children, especially young children, are considered to lack the self-awareness and competencies required to express their needs in an appropriate and accurate way (Kutnick, Ota, \& Berdondini, 2008). Children's Rights Perspectives (e.g. see Tisdall et al. 2009) challenge researchers to be competent in their interactions with children rather than focusing only on the competencies of the child.

In addition to skepticism over the reliability of children's evidence, concerns over the ethical challenges that researchers face may lead to children' being excluded from the research and development process (Harcourt and Einarsdottir, 2011). Concerns 
over ethical protocols, enhanced criminal records checks and suspicion about why adults want to spend time with young children may all lead researchers to conclude that the time and expense needed to overcome these challenges is a hindrance to achieving outcomes within the time and budgetary constraints of specific research projects.

If the rights of children, as laid out by the UNCRC (1989) are to be realized and if research is to be of a high quality which seeks to understand the communities in which it takes place, then children need to be included in research and these challenges addressed. In support of upholding children's participation rights, networks of practitioners and academics have continued to advocate for children's and young people's participation in both the global South and North and have continued to discuss methodological challenges in seeking to do this (for example see: Johnson, Ivan-Smith, Gordon, Pridmore, \& Scott, 1998). An example is the authors' development of six steps to engaging children in research (Johnson et al., 2014a). These steps are presented in the following section.

\section{Six Steps to Engaging Children in Participatory Research}

The authors' research involved the development of a framework of six steps for engaging children in participatory research. The steps were developed in collaboration with a team of researchers from the Global North and South. These researchers work in a range of academic and professional fields, including: streetwork, playwork, social work, childhood studies, education, psychology, counselling, sociology, and anthropology and geography.

Figure 1: Six Steps to Engaging Children in Participatory Research

Step 1: Consideration of capacity and capability

Step 2: Developing ethical protocols and processes

Step 3: Developing trust and relationships

Step 4: Selecting appropriate methods

Step 5: Identifying appropriate forms of communication

Step 6: Consideration of context

\section{Step 1: Consideration of Capacity and Capability}

At the outset of any research it is advised that the capabilities within the research team and the capacity of those involved, both as researchers and participants, is reviewed. From this understanding, areas where development and support are required can be recognized and a realistic research projects designed. In order to review the capacity and capabilities of researchers several factors need to be taken into account. These include, the experience the research team has of working with children (including their experience of implementing ethical protocols and procedures), the motivation for the inclusion of children and, their experience of using child-sensitive and participatory methods (Sargeant and Harcourt, 2012). It will be necessary for the research team to self evaluate their skills and identify areas in which they would benefit from support. There are various guides for facilitating participatory methods for working with children and these also review the approach to facilitation that is needed to engage with young children (for example, Boyden and Ennew, 1997 and Johnson, Nurick, Baker, \& Shivakotee, 2013). 


\section{Step 2: Developing Ethical Protocols and Processes}

Time needs to be scheduled into any research process to ensure that all members of the research team understand the ethical protocols which guide work with children, whether they be legal requirements, moral positions or specific cultural requirements (Alderson and Morrow, 2011). Time for training may therefore need to be built in to the research process.

If children are to participate in research in a meaningful way, they need to be engaged throughout the different stages of the research from planning to dissemination (Johnson, 2010b; Alderson and Morrow, 2011). There will be issues confronting researchers in conducting ethical research including power, authority, accountability and responsibility that may be even more marked when including young children in research (Morrow and Richards, 1996). Where there is more limited participation, researchers need to be aware of the level of participation they are aiming for and be clear in their accounts of research processes. Levels or degrees of participation can be understood using a variety of frameworks including Hart's (1992) 'Ladder of Children's Participation'. The ladder specifies different types of non-participation and participation from 'manipulation' and 'tokenism', to adult led initiatives in collaboration with children, to child led processes with adult support. Thus, levels or degrees of participation can be considered when planning children's participation in research processes that is voluntary, transparent and authentically relevant to their lives including considering who is initiating and controlling the process and who will have access to the data (Hart, 1992, 2007; Johnson et al., 2014a).

When developing ethical protocols and processes there are a number of issues which need to be considered. The following list of considerations may be a useful starting point (see Johnson et al., 2014a pp. 25-28):

1. Ensuring children's ownership of research throughout the research process

2. Making clear from the outset the level of participation children will have

3. Protecting all those involved in research from harm including researchers and children

4. Building trust and relationships with children in research so they feel supported

5. Understanding power relationships including between children and their peers and between children and adults

6. Including relevant processes of informed consent so children of differing ages understand why they are participating. This includes both informed consent from children and from their parents/guardians/ responsible adults

7. Respecting privacy and maintaining confidentiality so children are not put at risk

8. Following child protection policies and ensuring procedures are in place to support children at risk of psychological or physical harm

9. Taking into account issues of difference and inclusion into the research process

10. Ensuring there is adequate feedback to children and that children's questions are answered appropriately.

When developing ethical protocols and procedures in research, ethical guidelines drawn up by academic and professional bodies can be useful to follow; these may be particularly useful for those working in contexts in which there is little in the way of existing policies or agreed procedures. They can also eliminate some of the time and 
expense associated with the development of ethical procedures for working with children as they are often rigorously developed. Examples of such guidance are provided by the British Sociological Association (2002); the National Children's Bureau (2003); UINCEF (e.g. Graham et al., (2013). Whilst such guidance offers hugely valuable advice it is crucial that local contexts are sufficiently considered to ensure research is relevant to children's lives and conducted in an appropriate manner (Coles and McGrath 2010).

\section{Step 3: Developing Trust and Relationships}

Positive and supportive relationships are a pre-requisite for the development of understanding (Kutnick and Colwell, 2009) as such developing trust and respect between researchers and children is fundamental to the research process. In order for children to open up they need to trust researchers and feel supported by them (Punch 2002). If a safe and enjoyable environment can be built (see Colwell et al 2015), children usually feel more able to share their opinions freely. Such an environment can be established in three progressive stages: building trust; developing communication skills; and problem solving (Kutnick, et al., 2008). Such a process has been shown to lead to children being able to be more honest when sharing their opinions, whilst also developing the language needed to express their opinions; something which they may not often have the opportunity to do. This may help with the reliability of the information collected from children.

As researchers spend time with children developing their relationships they can also have the opportunity to come to understand the language of the children and the spaces which they inhabit. As such, researchers may better understand the evidence (Johnson et al., 2014). When carrying out research with young children power dynamics between researchers and participants need to be considered including intergenerational or adult-child relationships in which adult researchers may need to consider taking the aforementioned 'least adult role' (Mayall, 2002). Taking into account political, institutional and cultural contexts in which the research is taking place will also be important (as covered in step 6).

\section{Steps 4 \& 5: Selecting Appropriate Methods and Identifying Appropriate Forms of Communication}

These two steps are considered in tandem (Johnson et al., 2014a pp.35). Selecting appropriate methods and tools for collecting data will require consideration of both the requirements of the research, including what needs to be understood and over what time period, alongside what methods are appropriate for the children, including consideration of what is culturally and developmentally appropriate. When developing methods for engaging young children, researchers involved in developing these steps agreed that it can be helpful to cluster them by the different forms of communication they involve. That is, whether methods involve going into the spaces that children inhabit and play (in-situ) and understanding these spaces by accompanying the children or going on child-led tours, or using visuals alongside one-on-one or group discussions, or setting up processes of role-play and performance, or playing games made up with the children, for example. Considerations of methods requires planning the mediums that they require, be it paint, clay or dolls, for example. This can help to plan research that is more enjoyable, relevant and engaging for children and as such potentially increases the quantity and quality of the data they generate. The following clusters are suggested:

- Interviews and discussion

- Child-led tours and other in-situ methods 
- Visuals used with free expression and structured visual methods

- Narrative and performance

- Play and games including the use of dolls.

Although some of these methods are discussed in academic literature many have been developed and used in non-academic practitioner settings and so are written up in grey literature. This includes applied participatory research with children in nongovernmental organizations used to feed into planning development interventions or evaluation reports, examples of which are providing in the next section of this chapter. A good source of published literature on some of the more participatory and visual approaches to engaging children in research is the journal Participatory Learning and Action previously PLA Notes (particularly special issues 25,42 and 50 , see Chawla and Johnson 2004). These clusters of methods are discussed more fully in the following section of this chapter.

Selecting appropriate methods and tools will be key in ensuring the data is of a high quality and that it meets the requirements of the research. Personal, professional and ideological assumptions by both those funding or requesting the research and the researchers will need to be carefully considered (see for example Crotty, 2005). Perspectives on what 'counts' as evidence may differ between stakeholders, as such, during the planning phases the research team must clearly determine what kind of evidence will be valuable, what may generate the most appropriate form of data and whether decision-makers are prepared to accept children's evidence (see for example Eyben, Guijt, Roche, \& Shutt, 2015). Working with funders and decisionmakers during the planning and development phase to highlight why children's evidence should be taken seriously and how their evidence will be used may support the research process (Johnson 2015). All too often children's evidence can be ignored or the value of their data queried at a later stage and so sidelined in preference to other forms of data from adults about children.

\section{Step 6: Consideration of Context}

Research that engages with children needs to be relevant to their lives. Therefore attention must be given to political, cultural and institutional contexts prior to any data collection processes being finalized. As part of this analysis, researchers need to begin to understand existing power dynamics, attitudes towards children, cultural practices and belief systems, in order to plan ethical research processes that work for children and that are more likely to be acceptable to the adults in their lives. How children will participate will also depend on their interactions with others and what they feel is expected of them: these issues will all affect how children feel about contributing to evidence about their lives, feelings and opinions (Johnson et al., 2014a pp. 66, Johnson 2015). This again highlights the significance of the relationships that researchers build with the children and adults in communities and also their awareness of incorporating analysis of socio-cultural context. Taking into consideration the spaces that children inhabit and the reality of their daily lives, including how they spend their time playing, learning and working, will be crucial when seeking to plan appropriate research. Researchers should therefore be mindful of the variety of roles that children fulfill including contributing to the household economy through farming and paid labor, for example, working in factories (Evans, 2010). Recognizing the importance of the contexts in which children's participation is situated and the roles children take within that context is key to taking children's perspectives seriously in research (Mason and Bolzan 2010). 


\section{Methods for Engaging children in Participatory Research}

This section offers an overview of the clusters of participatory methods noted in step 5. Some examples have been provided as case studies to demonstrate how these methods have been used in a range of contexts to understand children and young people's lives and the spaces and places that they inhabit. Whilst also highlighting some of the benefits and challenges of these methods. The case examples have been selected as the authors feel they may be particularly useful to researchers working to understand children's geographies. Further details of the case studies and additional examples can be found in Johnson et al. (2014a and 2014b).

\section{Interviews and Discussion}

While interviews may often seem to be the most obvious choice for research purposes, they may require special attention to make them appropriate for use with children. This includes making interviews less formal than they may be when used with adults, using certain props or materials alongside interviewing or by combining interviews with other methods of engaging children. For example: interviewing children as they draw (Kanyal, in Johnson et al., 2014); or with toys and models such as by geographers understanding children's living and play spaces (Hart,1979).

In addition, rather than directing a child to answer questions in an interview format, practitioner researchers who spend sustained amounts of time with children, are able to situate themselves as observers of children's activities over a period of time and engage in 'listening to children' (Clark and Moss, 2011). These opportunities to observe and listen may be carried out in a child's everyday environment. In their own familiar setting, in a childcare setting for example, it is often possible to talk to young children as they engage in familiar activities. However the setting should be considered. For example, if research is in a school, where children are commonly led to believe there is a correct answer for everything, they may be unlikely to express opinions which they feel do not align with adults expectations, particularly if they fear they may be reprimanded. Spending time with a child, developing a trusting relationship, may make a difference to how comfortable children feel and thus how open they are within the interview.

It has been asserted that young children's early concept formation is in the form of scripts and they are able to express their thoughts more fully in the from of a narrative than in the question and answer format traditionally used in interviews (for example see Engel, 1995; Greene and Hogan 2005). Indeed, the narrative inquiry approach is becoming more common as method for listening to research participants of all ages and there is a growing literature on the subject (for example see Daiute, 2014). As such researchers may find it beneficial to find ways to support children to tell stories about the phenomena they are interested in. Of course this may lead to children diverging from the topic. Listening to a child, there may be a relevant message within their narrative, and then gently guiding a child back to the research topic will be the task of a skilled researcher.

Whether interviews are conducted with individuals or in groups depends upon the research topic, the requirements of the project and crucially, what is deemed most appropriate for the child(ren). When the research questions concern children's shared experiences of a common space such as a playground, or a shared experience of an activity, interviews with dyads or with small groups may be useful. Group interviews often create a more informal setting that brings out a fuller account of children's relationships to the space or activity and may help researchers to verify information and understand consensus views (Lewis, 1992). However, sensitive 
issues may be raised in interviews conducted with groups of children and it may be considered more appropriate to conduct such interviews in a one-to-one environment (see for example Robson, 2001). It may sometimes be beneficial in research processes to conduct both group and individual interviews to explore different issues with children (Lewis, 1992).

\section{Case 1: Children's Agency in Addressing Water Supply in Tibet}

A range of methods including children being encouraged to express their views through group interviews were used to help address water supply problems in Tibet (West in Johnson et al. 2014a). The project involved working with children on how they would like to participate in a water and sanitation programme run by Save the Children. With children being consulted throughout the process, a variety of tools were developed with children's participation in how engaging they were. The researchers found that using a range of techniques to support the discussions helped the children to remain involved in the process and for the researchers to gain more detailed information. This included using drawings and models. Particular to this context the research team found that conducting the discussions in both English and Chinese increased children's participation. Through involving children in discussions over time, their understandings and confidence grew and they were able to contribute to the planning of the water sanitation programme. This in turn served to change adults' ideas about children's agency to recognize their ability to analyze information and to take local action.

\section{In-situ Methods and Child-led Tours}

Conducting research with a child in-situ can place them closer to the experiences that they are talking about than conducting research in a more conventional interview setting (Kusenback, 2003). The term child-led tours (see case 2) describes mobile interviews carried out as a child (or group of children) takes a researcher through a space to describe experiences that happen(ed) in that space or to annotate aspects of the space that mean something in particular to the child or children leading them. These mobile interviews or child-led tours can be particularly useful for understanding the geography of children and how they access and inhabit their environment (e.g. Hart, 1979; Lynch, 1979 and Driskell, 2002; see also Ponto's chapter in this volume). Mobile interviews have also been used to understand children and young people's roles in household chores and work contributing to household economies where researchers accompany children in their daily activities (Johnson, Ivan-smith \& Hill, 1995). Ethical issues, such as researchers taking children away from a formal environment, that is, conducting research away from groups where other familiar adults are present, will require specific consents, planning and safe guarding.

Photography with still cameras or videos made by children can help to document child-led tours (for example, the work of 'photovoice' www.photovoice.org; Murray in Johnson et al., 2014b). The use of photographs taken by children has been used for many years e.g. Hart, 1979), but the method has dramatically increased with the arrival of inexpensive disposable and digital cameras. The method quickly enables children to begin to show their worlds (for example see Einarsdottir, 2005; Evans, 2006), but it is not without challenges: it is worth taking a critical stance on what children are wanting to say rather than focusing too much on the photograph itself. There is an increasing body of research building on this method, such as audio- 
recorded annotations of photographs, and exhibitions and booklets made by children with commentaries. A valuable example of how far the method can take a researcher into the worlds of those children who might normally have little or no opportunity to share their perspectives is offered by Luttrell (2010).

Audio equipment can also be used to capture children's opinions as they show researchers through a space or place but it is often difficult to link the sound to particular places. If a transect or set route is used then different perspectives can be gathered about the same space or the tour or interview can be more determined by a child or children. This idea of leading the researcher through a space can be applied in a simulated form, as when a child takes a doll through a model of a space or place to express their feelings about this.

\section{Case 2: Child-Led Tours in India}

In India, group child-led tours were conducted in order to understand existing and redeveloped slum areas in Mumbai and Bangalore (Nallari in Johnson et al., 2014a). These tours showed where children play, what services they knew about and could access, and how they and their caregivers use local common spaces such as parks. The child-led tours in India consisted of around four boys and four girls between the ages of six and 16 years although adolescent girls were rarely allowed to leave their houses so did not often participate. Tours were recorded by researchers with hand-held video cameras and children would lead and stop when they wanted to discuss a particular place. Nallari (in Johnson et al. 2014a) noted that the method worked well and children's voices where captured. It was noted that when working with children of mixed age groups, as was the case here, using methods understood by the youngest members was most advantageous. Where methods were used to appeal to the older children the younger children were often left out. Where methods were accessible to all, greater focus was maintained.

\section{Visual methods including mapping}

A range of visual methods have been used for many years by both anthropologists (for example Boyden and Ennew, 1997 and Reynolds, 1991) and geographers (for example Hart, 1979, 1997 and Young and Barrett, 2001) to understand children's everyday lives in households and on the streets and how they interact with their environments in urban and rural settings. Visual methods may be thought of as two major types: those where children have complete freedom to express themselves with the medium, and visuals that are structured in some way by the researchers (Johnson et al. 2014b). Young and Barrett (2001) note that visual methods support young children with a high-level of involvement in research.

Visual methods for free expression include drawing and model making using different media, including sand, clay and other available resources. Model making has benefits for some types of representation, such as mapping (see case 3), because, unlike drawing, the materials can be easily moved around until the child is happy with their decision of where to place something. Drawings however require a commitment that is not so easy or flexible to erase (Hart, 1979,1997). For a similar reason, modelmaking is more suited than drawing for group use. Because of these benefits models have been used very effectively in urban planning processes that simultaneously include people of a wide range of ages (for example in an approach called planning for real: www.planningforreal.org.uk). Model making can also be valuable for 
surmounting barriers for non-literate children who are not comfortable using pens and paper.

Visual structures and templates have been used for many years by international organizations working in development in the form of 'Participatory Appraisal' (PA) and 'Participatory Action Research' (PAR). PA lies partially in Freirean philosophy relating to literacy and empowerment expressed as the 'pedagogy of the oppressed' (Freire, 1972). It also builds on qualitative including visual methods and actionorientated approaches from the tradition of 'Participatory Action Research'. PA also incorporates ideas and methods from anthropological ethnographic research and diagrams developed for appraisal in agroecosystems analysis. Visuals can, however, be used in extractive as well as participatory ways so the PA approach has been rife with tensions about the way in which visual methods are applied in research processes. There has been a growing more recent discourse about how participatory appraisal methods need to take more account of power dynamics in order to achieve more transformative development (Hickey and Mohan, 2004; Johnson, 2011). The approach spread rapidly over several decades and was often effectively developed for community use by practitioner researchers working in the field of international development as well as by social scientists (for example Chambers, 1983, 2003; O'Kane, 2000). Participatory appraisal methods have been used with adults, and also, less extensively, with children, to understand community development interventions and impact (for example Guijt, Fulglesang \& Kishadha, 1994, Johnson et al., 1995, Johnson, 2010b). Occasionally PA has been used with very young children and to explore issues in the early years. For example research on childcare with Save the Children Nepal used household mapping to understand the different perspectives of both caregivers and children of their living spaces and the quality of housing (Arnold, Bartlett, Hill, Khatiwada, \& Sapkota, 2000). As well as being trained in early childhood development, researchers were trained in carrying out participatory methodologies with children.

Examples of visual participatory methods include participant drawn maps and 'physical mapping' using local materials. Maps can be drawn or constructed by individuals or groups of participants and be the focus for further discussion on issues, such as safety, places where people work, socialize and live, use of services and support networks, likes and dislikes relating to public and private spaces, and territoriality. They can also lead to planning changes that participants would like in their communities. It is also possible to use base maps to enable children to express their views including their evaluations of their communities. This involves providing a map and asking the child to take the researcher through that map. Urban planners have also used visual methods such as mapping to understand neighborhoods and the use of public spaces by different people including children in communities in order to inform planning and design (Chawla, 2002). In addition, with technological advances there has been an increase in the use of mapping with mobile devices, video cameras and for more details on this, see Donovan in this volume).

While mapping has obvious appeal to children's geographers, there are also other visual diagramming methods that can help to understand children and young people's roles in households and societies and the ways in which they use and manage environments. These include transects, daily activity charts, seasonal calendars, preference ranking of activities and experiences, network diagrams and flow charts (Kindon et al., 2007; Kesby, 2000; Johnson et al., 1995). Visual diagramming can help to overcome unequal power dynamics between children and researchers especially in cultural contexts where especially girls may not feel that their opinions would be valuable (Sapkota and Sharma, 1996). For example in the UK visuals, including physical mapping, food/ mood lines and diaries, and drawing 
the last meal eaten were used as a way for those who had been marginalized in society and decision-making processes to participate in research which fed into the regeneration planning of their communities (Johnson and Webster, 2000).

Detailed ethnographic research can be combined with the use of Participatory Appraisal visuals, for example research carried out with ActionAid Nepal to explore children's roles in households and societies and their use of the natural environment (Sapkota and Sharma, 1996). More traditional use of interviews and observation was combined with accompanying children (aged 5 years upwards) during their everyday activities and work and by using visual methods such as mapping, seasonal work calendars, preference ranking and flow diagrams. Mapping was used to understand the local environment and what resources and services there were in the area. Mobility mapping that shows from a central point, how far children travel and where boys and girls go each day for play, schooling and household chores/work. The mobility maps clearly showed the gender preference in the high hill areas where the research was carried out to send boys to school and gave an indication of where children travelled to in order to collect water and fuelwood, look after animals, help with farming and to carry out paid work for their household. Preference ranking was then used to understand the type of work that girls and boys least liked, including heavy digging and collecting wood, and chores that were not thought to be as bad, such as washing pots and pans and looking after livestock in the fields. Seasonal calendars enabled researchers to understand the way in which children's routes to school and work changed during the monsoon period when rivers were flooded and how their work loads changed at different times of the year. Flow diagrams also helped to explore environmental and social changes and the impact on children's lives. Power dynamics associated with gender rooted in cultural systems of dowry and traditional beliefs and roles in households varied in different caste and ethnic groups and were essential to understand the complexity of children's experiences and how they fitted into households and local communities. The research with young children was therefore carried out in parallel with research with other members of the households using interviewing and participatory visuals and interviews with key informants in communities, civil society organizations and local government.

\section{Case 3: Mapping children's environments in Japan}

Kinoshita (e.g. 2009) has used mapping with young children to understand their experiences of play spaces. In this project Kinoshita explored the use of maps with young children and compared these with the maps of adults from different generations. This allowed an understanding of how the use of spaces has altered overtime. Kinoshita was able to use similar mapping techniques across the generations. For the youngest children subtle differences were made. In the first instance children were encouraged and given space to talk about their play. As they spoke their parents helped them to indicate where these spaces were on map. It was important to ensure that the child was allowed to speak and that the parent only indicated the spaces the child referred to, rather than adding to the discussion. In addition Kinoshita found that if the child was first given time to draw their play spaces and activities and then ad them to a map with their parents support it allowed them greater control and involvement in the research process.

\section{Performance and Narrative}

There is a difference between the words in a narrative that children construct in response to research questions and the narrative that they use in their everyday lives that researchers can observe and record (Engel, 2005). There needs to be a 
distinction in collecting narratives and using performance and role-play to understand children's lives or their perceptions about different issues and performance and drama that is constructed by or with adults for educational purposes. When used as a participatory way to construct meaning with children, performance and narrative methods can be an excellent means for obtaining a rich understanding of children's experiences and many children find these methods enjoyable. For example in storytelling children can tell stories that they have heard or they can construct their own stories about their life experiences. One strength in dialogue based methods is that children may be familiar with these in their every day lives.

Performance may include drama, role-play, poems and puppets. There can also be silent drama, mime and dance that can also be used to portray feelings about places, people and things and can be particularly inclusive in involving some children with learning difficulties or special educational needs. Drama generally means that there is a structure and story compared with role-play which is a more free form exploration generally designed to reveal how children feel about a particular situation or incident.

When working in different cultural settings there needs to be an empathy with participants so that both children and adults involved are prepared for the use of performance in research (West, O'Kane, \& Hyder 2008; Belloni and Carriero, 2008). There also needs to be a cultural understanding of the use of drama and narrative in the local cultural context so that researchers understand when children are following set formats or when they are freely expressing themselves through performance. In order to write up and analyze evidence provided in narrative and performance it is important that researchers understand not only direct translations of words but also the overall context of the discourse including the setting and actions that accompany the delivery. As in interviews, prompts may also be used as in interviews to stimulate discourse. Experience of the language and culture will be vital in this process.

Performance and narrative can be used to understand children's feelings about their experiences of their context (Case 4), local environment and the spaces that they inhabit. They are also effective methods for gathering evidence about interactions between different people and groups within societies as perceived by children. Given the range of situations they can be used to explore and the fact that children are often familiar with and enjoy such methods, they can be extremely valuable tools for a researcher.

\section{Case 4: Critical Self Reflection On Group Organisation by the Children's Clubs of Nepal}

Designed to document how children's clubs in Nepal functioned this project (see Rajbhandary, Hart, \& Khatiwada, 1999) used methods that could be used simultaneously by a large number of children across a wide age range. The research team found that it is important to recognise that when working with children of mixed ages in groups, the young children are often able to think and have dialogue with the older participants at a higher level than they can have in groups made up entirely of their own age group, thus this can be very beneficial when considering research with young children. Whilst this research processes involved a number of methods of specific interest here was the use of 'scenario skits' or performance to allow children to explain their experiences and perspectives.

The research team suggested different scenarios and asked the children to create a play about each of them. The dialogues generated during the performances were analysed and later shared with the children, to gain an 
understanding of their lives. This method is flexible as the research team can select the topic of the performance. The children used all aspects of performance, including dance, to express their views. They however rejected the use of puppets as they found that these constrained the process.

\begin{abstract}
A large quantity of data was collecting using this method. The research team reported that the incorporation of physical activity seemed to greatly increase the youngest children's interest and participation. However, they also found that it was beneficial to separate the children into age ranges for discussions of the data to allow each group of children an opportunity to speak.
\end{abstract}

The team also noted that because the performances were time consuming, there was often insufficient time for the analysis and interpretation of the scenarios by the children; the method itself became too much of the focus. Highlighting how time needs to be well planned in order for performance to work well as a data collection tool.

\title{
Play and Games
}

Play and games provide a developmentally appropriate way to carry out research with young children because it is what they choose to do most of the time when they are free to do so (Green, 2007). Play may be part of any successful research engagement with this age group and has been recognized as an integral part of children's rights as specified in the UNCRC. Piaget referred to play as the language of childhood and suggested that children needed to 'play things through' in the way that adults may think things through (Piaget and Inhelder, 1962, p.57). As such, play and games are recognized as being an important way to engage children in research to understand their lives (Boyden and Ennew, 1997) as well as being a central aspect of children's development (Bodrova and Leong, 2005). It is important though that researchers ensure that play in research does not become a burden for children (Alderson, 2000) taking the pleasure or freedom away from the child.

There are various different types of play that are identified in contemporary psychological literature: physical play, play with objects, symbolic play, pretense and socio-dramatic play, and games with rules (Whitebread, Basilio, Kuvalja \& Verma 2012). Many of these forms of play resonate with the clusters of methods already considered within this chapter. Physical play can take place indoors or outdoors and is often culturally specific. Play that uses objects can be useful for social scientists who want to understand how children feel about decision-making (Alderson, 1993). Symbolic play is also linked in that objects are used to represent people and things (see case 5) and can also be useful when children are recounting painful experiences for example relating to conflict (Ennew and Plateau, 2004).

Observing play and games can help researchers to understand children's thinking and their preferences (Foreman and Hall, 2005) whilst also providing a developmentally appropriate way to carry out research and understand issues about children's lives (Green, 2007) Observation of children in symbolic play, in which objects are used to represent people and things (see cases 5 and 6) can be particularly useful in geographic research for gaining insights into children's knowledge and experience of the physical environment (for example Hart, 1976; Katz, 2011).

\section{Case 5: Using Persona Dolls in South Africa}

Persona dolls are large (72cm tall), lifelike, culturally sensitive dolls. They are 
dressed like children and may have props to extend their personas, for example by wearing a Muslim headscarf, glasses, or using a wheelchair. Larger dolls have more impact as they are more lifelike. Dolls can easily be improvised, be made from cardboard and paper clothed.

Bersteker and Smith have used persona dolls to initiate discussion, explore children's opinions and feelings about different topics, specifically children's perceptions and experience of difference including race, class, ability and disability (see Biersteker with Smith in Johnson et al., 2014b).

The research process followed distinct phases to ensure that the young children were comfortable. In the initial sharing of the dolls the children were supported to engage with the dolls - greeting, hugging or stroking and speaking to them. They also enjoyed telling the facilitator and other children what they thought the doll was saying when they imitated it whispering into their ears. The children were asked to guess the name, family structure, language, where they lived, what they would like to do while visiting at the preschool. What would make her/him happy or sad?

In the following phase a doll was brought out and the children were told the doll had a problem. Through the example of the doll the children then discussed their own experiences, feelings about this and advice they would give the doll. One example of a problem was that the doll had been chased from the doll corner where he wanted to play nurse. Because he was a boy, he was teased by some of other boys. Using stories in this way helped the researcher to document children's responses to situations and plan to support their development.

Biersteker and Smith found there are some challenges to this method for example, that it is important that the doll has as few characteristics as possible, unless it is the characteristic that is being explored. This helps to ensure the child's view is not shaped by any stereotypes and always them to protect on to the doll. In addition, they found there can be some difference in the way children of different sexes approach the task, they state that this relates to stereotypes related to the appropriateness of males playing with dolls. This may need to be addressed at the outset of the research.

Conversely, persona dolls provide an open-ended stimulus for discussion on a range of topics of interest to children and so can be a hugely valuable research tool.

\section{Case 6: Medical Dolls in Canada}

Hospital Play Dolls are highly adaptable soft cloth dolls that come in a variety of skin shades and are normally used with children who have chronic medical conditions. They provide opportunities for emotional expression and mastery over health care experiences. Medical dolls can be used to initiate dialogue and gain children's perspectives regarding medical and social conditions. As well as being used to educate they can also explore children's emotions, social responses and fears, for example the work of $\operatorname{Koller}(2007,2008)$. This makes them a potentially useful tool in a variety of contexts and purposes.

In Canada and the USA Koller (ibid) has used medical dolls to help children in hospital to share their feelings and experiences. Initially the children completed the dolls by using a variety of materials such as markers, paint, fabric, beads etc giving them a bind to the doll. This method can be used with 
individual children or small groups of about four children. Similar to the persona dolls, these dolls can became quite animated or 'life like' as the children whispered comments to them, or asked the facilitator to tell them what the doll was saying. For research questions involving children's understanding of medical conditions, or their health care experiences, the dolls provide the context in which to directly address these issues. Children can point to the doll to explain for example, pain or procedures such as surgeries and stitches and then talk through their feelings using the doll as an intermediary. Having this intermediary can help young children by having a 'body' to guide them through the discussion and help them to explore their emotions with some degree of distance.

\section{Conclusions for Engaging Young Children in Research}

Valuable evidence can be collected from young children about their experiences and their knowledge of the world. Indeed as the examples in this chapter have indicated excluding children from discussions can have a negative and potentially detrimental impact on their lives. The steps provided, whilst not intended as a recipe to eliminate the challenges of including young children, offer guidance as to the issues that a researcher and/or research team will need to consider as they embark on research. It is proposed that researchers working with children need to carefully plan how they will undertake their research and how they will adapt methods as necessary so as to ensure children's voices are being captured. By opening up to a broader range of methods for enabling children to communicate their experiences and their interactions with the spaces that they inhabit can be increased. These methods can be fun and playful, but also provide rigorous evidence through which children can contribute to new knowledge about children's geographies and to decision-making processes that may have an impact on their lives.

The development of steps to engage young children in research serves to increase praxis through sharing theoretical understandings and practical experiences of researching with young children in global contexts. The steps were developed with international researchers in children's participation from the global North and South, working across a range of academic and practitioner settings. This provided a forum to exchange ideas and build on existing approaches to engage with young children to understand their complex lives and geographies. This chapter is part of that process of sharing and further developing ideas about how to engage children in research. Increased capabilities and confidence of researchers in a variety of political, cultural and institutional contexts can be continued through continuing to share learning and by supporting communities of practice that are contributing to new knowledge about children's lives in an ever changing world. This can in turn provide decision-makers with a more complete understanding that the evidence needed to inform and develop policies and interventions to realize child rights internationally includes the includes the perspectives of young children.

\section{References}

Alanen, L. and Mayall, B. (2001). Conceptualizing Adult-Child Relations, The Future of Childhood Series, London and New York: Routledge/ Falmer.

Alderson, P. (2000). Young Children's Rights: Exploring beliefs, principles and practice. London: Jessica Kingsley. 
Alderson, P. (1993). Children's consent to surgery. Buckinghamshire: Open University Press.

Alderson, P. and Morrow, V. (2011). The Ethics of Research with Children and Young People: A Practical Handbook. London: Sage Publications.

Arnold, C., Bartlett, S., Hill, J., Khatiwada, C. and Sapkota, P. (2000). Bringing Up Children in a Changing World. London/Paris: Save the Children and UNICEF.

Bartlett, S. (2005). Good Governance: Making age part of the equation - an introduction. Children, Youth and Environments. 15 (2), 1-17.

Belloni, M.C. and Carriero, R. (2008). Childhood: a homogeneous generational group. In Leira, A. and Saraceno, C. (eds) Childhood: changing contexts Comparative Social Research 25, 293-324, Bingley: Elsevier/ Emerald

Bodrova, E. and Leong D. (2005). The importance of play, why children need to play. Early Childhood Today, 20 (3), pp. 6-7.

Bourdillon, M. (2004). Children in Development. Progress in Development Studies 4(2), pp. 99-113.

Boyden, J. and Ennew, J. (eds.) (1997). Children in Focus: A Manual for Participatory Research with Children. Stockholm: Save the Children.

British Sociological Association (BSA) (2002). Statement of Ethical Practice. Durham: British Sociological Association.

Bronfenbrenner, U. (1979). The Ecology of Human Development: Experiments by nature and design. Cambridge, Ma: Harvard University Press.

Cahill, C., Hart, R. (2007). Rethinking the boundaries of civic participation by children and youth in North America. Children, Youth and Environments. 17(20, pp.213-225.

Chambers, R. (1983), Rural Development: Putting the last first, Addison Wesley Longman Ltd. Harlow, UK

Chambers, R. (2003). 'Reflections on PRA Practice' in Cornwall, A. and Pratt, G. (2003) Pathways to Participation: Reflections on PRA, ITDG Publishing, UK

Chawla, L. (Ed.) (2002). Growing Up in an Urbanising World. Paris / London: UNESCO Publishing / Earthscan.

Chawla, L. and Johnson, V. (2004). Not for Children Only: Lessons learnt from young people's participation. In Critical Reflections, Future Directions, PLA Notes, 50, International Institute of Environment and Development (IIED), London.

Christensen, P. and James, A. (2008). Research with children: Perspectives and practices, ( $2^{\text {nd }}$ edn), Oxon: Routledge.

Clark, A. (2005). Listening to and involving young children: a review of research and practice, Early Child Development and Care, 175(6), 489-505.

Clark, A. and Moss, P. (2011). Listening to young children: The mosaic approach (2nd edn.). London: National Children's Bureau Enterprises Ltd. 
Coles, A. and McGrath, J. (2010). Your Research Project Handbook. Harlow UK: Pearson Education.

Colwell, J., Beaumont, H., Bradford, H., Canavan, J., Cook, E., Kingston, D., Linklater, H., Lynch, S., McDonald, C., Nutkins, S., Ottewell, S., Randall, C. and Waller, T. (2015) Reflective Teaching in the Early Years. Bloomsbury: London

Crotty, M. (2005). The foundations of social research: Meaning and perspective in the research process. Sage Thousand Oaks, CA.

Daiute, C. (2014). Narrative Inquiry: A Dynamic Approach. Thousand Oaks CA: Sage

de Smith, M. J., Goodchild, M.F. and Longley, P.A. (2015). Geospatial Analysis A Comprehensive Guide to Principles, Techniques and Software Tools (5th edn) Winchelsea: Winchelsea Press.

Driskell, D. (2002). Creating Better Cities: With Children And Youth: A Manual For Participation. Paris/London: UNESCO Publishing/Earthscan Publications.

Einarsdottir, J. (2005). Playschool in Pictures: Children's photography as a research method. Early Child Development and Care 175, 523-541.

Engel, S. (1995). The Stories Children Tell: Making Sense of the Narratives of Childhood. New York: WH Freeman.

Ennew, J. and Plateau, D.P. (2004). How to research the physical and emotional punishment of children. Bangkok: International Save the Children Alliance.

Evans, R. (2006) Negotiating social identities: the influence of gender, age and ethnicity on young people's 'Street Careers' in Tanzania. Children's Geographies, 4 (1), 109-128.

Evans, R. (2010). Children's caring roles and responsibilities within the family in Africa. Geography Compass, 4(10), 1477-1496.

Eyben, R., Guijt, I., Roche, C., Shutt, C. (2015). The politics of evidence in international development: Playing the game to change the rules. Rugby: Practical Action Publishing.

Foreman, G. and Hall, E. (2005). Wondering with Children: The Importance of Observation in Early Childhood. Early Childhood Research and Practice in Early Education. 7(2) Available at: http://ecrp.uiuc.edu/v7n2/forman.html. Accessed on 12th May 2014.

Freire, P. (1972). Pedagogy of the Oppressed, Penguin Books, London

Graham, A., Powell, M., Taylor, N., Anderson, D. \& Fitzgerald, R. (2013). Ethical Research Involving Children. Florence: UNICEF Office of Research - Innocenti. Available at: http://childethics.com/wp-content/uploads/2013/10/ERIC-compendiumapproved-digital-web.pdf

Green, E. J. (2007). The crisis of family separation following traumatic mass destruction: Jungian analytical play therapy in the aftermath of hurricane Katrina. In 
N. B. Webb (Ed.) Play therapy with children in crisis: Individual, group, and family treatment (3rd ed., 368-388). New York, NY: The Guilford Press.

Green, S., and Hogan, D. (2005). Researching Children's Experiences: Approaches and methods, London: Sage

Guijt, I., Funglesang, A. and Kishadha, T. (ed.) (1994). It is the Young Trees that make a Forest Thick. London: IIED, and Kampala, Uganda: ReddBarna.

Hanson, K. and Nieuwenhuys, O. (Ed.) (2013). Reconceptualizing Children's Rights in International Development: Living Rights, Social Justice and Translations. New York: Cambridge University Press

Harcourt, D. and Einarsdottir, J. (2011). Introducing children's perspectives and participation into research. European Early Childhood Education Research Jour nal.19(3), 301-307.

Hart, R. (1979). Children's Experience of Place. New York: Wiley.

Hart, R. (1992). Children's Participation: From tokenism to citizenship, Innocenti Essay No. 4, Florence, Italy: UNICEF International Child Development Centre.

Hart, R. (1997). Children's Participation: the Theory and Practice of Involving Young Citizens in Community Development and Environmental Care, New York: UNICEF, and London: Earthscan.

Hart, R. (1998). 'The Developing Capacities of Children to Participate'. In Johnson et al. (ed.) (1998). Stepping Forward: Children and young people's participation in the development process. London: IT Publications. 27-31.

Hickey, S. and Mohan, G (eds.) (2004). Participation: From Tyranny to

Transformation? Exploring new approaches to participation in development. London: Zed Books.

Johnson. V. (2015). Valuing Children's Knowledge: The politics of listening. In Eyben, R., Guijt, I., Roche, C., Shutt, C. (2015). The politics of evidence in international development: Playing the game to change the rules. Rugby: Practical Action Publishing.

Johnson, V. (2014). Change-scape theory: applications in participatory practice. In Westwood, J., Larkins, C., Moxon, D., Perry, Y, and Thomas, N., (eds), Citizenship and Intergenerational Relations in Children and Young People's Lives: Children and Adults in Conversation, Palgrave Pivot: Basingstoke

Johnson, V. (2011). 'Conditions for Change for Children and Young People's Participation in Evaluation: 'Change-scape', Child Indicators Research, Springer Vol. 4(4)5, 77-596

Johnson, V. (2010a). 'Revisiting Children and Researchers in Nepal: What facilitates and hinders change in a context of conflict and the changing political economy', Journal for International Development, Wiley, Vol. 22 No. 8 pp 1076-1089

Johnson, V. (2010b), Rights through Evaluation and Understanding Children's Realities. In Percy-Smith, B. and Thomas, N. (2010), A Handbook of Children and 
Young People's Participation: Perspectives from Theory and Practice, Oxford: Routledge

Johnson, V., Hill, J. and Ivan-Smith, E. (1995). Listening to Smaller Voices: Children in an Environment of Change. London: ActionAid.

Johnson, V., Hart, R. and Colwell, J. (eds) (2014a). Steps to Engaging Young Children in Research: The Guide, Vol. 1. The Hague: Bernard van Leer Foundation. Available at: http://www.bernardvanleer.org/files/Steps-to-Engaging-Young-Childrenin-Research-vol-1.pdf. Accessed 1st February 2015.

Johnson, V., Hart, R. and Colwell, J. (eds) (2014b). Steps to Engaging Young Children in Research: The Researcher Toolkit, Vol. 2. The Hague: Bernard van Leer Foundation. Available at: http://www.bernardvanleer.org/files/Steps-to-EngagingYoung-Children-in-Research-vol-2.pdf. Accessed 1st February 2015.

Johnson, V., Ivan-Smith, E., Gordon, G., Pridmore, P. and Scott, P. (1998). (eds.) Stepping Forward: Children and Young People's Participation in the Development Process. London: IT Publications.

Johnson, V., Hill, J. and Ivan-Smith, E. (1995). Listening to Smaller Voices: Children in an Environment of Change, London: ActionAid

Johnson, V., Nurick, R., Baker, K, and Shivakotee, R. (2013). Children and Young People's Participation Training Workshop Guide. London and Brighton: ChildHope and Development Focus.

Johnson, V., Johnson, L., Magati, B. O., Walker, D. (2016). Breaking intergenerational transmissions of poverty and spaces for rehabilitation from the perspectives of street-connected girls in Nairobi. Intergenerational Mobilities: Relationality, age and lifecourse. Farnham: Ashgate

Johnson, V. and Webster, J. (2000). Reaching the Parts.... Community mapping: Working together to tackle social exclusion and food poverty, London: Sustain - The Alliance for Better Food and Farming.

Katz, L. (2011). "What is a 'Good' Childhood?” Researching Children, Global Childhoods and Education Conference, The Graduate Center of The City University of New York, 24-26 March.

Kesby, M. (2000). Participatory diagramming as a means to improve communication about sex in rural Zimbabwe: a pilot study. Social Science and Medicine 50 (12) 1723-1741.

Kinoshita, I. (2009). Charting Generational Differences in Conceptions and Opportunities for Play in Japanese Neighborhoood, Journal of Intergenerational Relationships, vol,7(1), Routledge, 53-77.

Kindon, S., Pain, R., and Kesby, M. (eds) (2007). Participatory action research approaches and methods: Connecting people, participation and place. Oxon: Routledge.

Koller, D. (2008). Therapeutic play in pediatric health care: The essence of child life practice. Child Life Council Evidence-Based Practice Statement. Peer reviewed and 
approved by the Child Life Council, Maryland, USA. Available online at www.childlife.org.

Koller, D. (2007). Preparing children and adolescents for medical procedures. Child Life Council Evidence-Based Practice Statement. Peer reviewed across North America and approved by Child Life Council, Maryland, USA. Available online at www.childlife.org.

Kutnick, P. and Colwell, J. (2009) Relationships and dialogue enhancement: the relational approach, in $\mathrm{C}$. Howe and K. Littleton 9eds) Educational Dialogue: understanding and promoting interaction, London: Routledge.

Kutnick, P., Ota, C. and Berdondini, L. (2008). Improving the effects of group working in classrooms with young school-aged children: facilitating attainment, interaction and classroom activity. Learning and Instruction, 18(1), 83-95.

Kusenback, M. (2003). Street phenomenology: the go-along as ethnographic research tool. Ethnography. 4(3), 455-485.

Lansdown, G. (2010). The Realisation of Children's Participation Rights. In PercySmith, B. and Thomas, N. (2010), A Handbook of Children and Young People's Participation: Perspectives from Theory and Practice, Oxford: Routledge. 11-23.

Lewis, A. (1992). Group Child Interviews as a Research Tool. British Educational Research Journal, 18(4), 413-421.

Luttrell, W. (2010). A camera is a big responsibility: a lens for analyzing children's visual voices. Visual Studies, 25 (3), 224-237

Lynch, K. (1979). Growing Up in Cities. Cambridge, Mass: MIT Press.

Mason, J. and Bolzan, N. (2010). Questioning Understandings of Participation. In

Percy-Smith, B. and Thomas, N. (2010), A Handbook of Children and Young

People's Participation: Perspectives from Theory and Practice, Oxford: Routledge. 125-132.

Mason, J. and Fattore, T. (eds), (2005). Children taken seriously: in theory, policy and practice. Jessica Kingsley, London.

Mayall, B. (2000). The Sociology of Childhood in relation to Children's Rights. The International Journal of Childhood Rights. 8(3), 243-259.

Mayall, B. (2002). Conversations with Children. Working with general issues. In Christensend, P. and James, A. Research with Children: Perspectives and practices. London: Falmer/ Routeldge.

Mertens, D.M. and Ginsberg, P.E. (Eds) (2008). The Handbook of Social Research Ethics. London: Sage.

Morrow, V. and Richards, M.P.M. (1996). The ethics of social research with children: an overview. Children and Society 10(2), 90-105.

National Children's Bureau (2003). Guidelines for Research, available at http://www.ncb.org.uk/ourwork/research_guidelines.pdf. Accessed 10th January 2014. 
Nieuwenhuys, O. (2005) Children's Lifeworlds: Gender, Welfare and Labour in the Developing World. London: Routledge.

O'Kane, C. (2000). The Development of Participatory Techniques: Facilitating children's views about decisions that affect them. In P. Christensen and A. James Research with Children: Perspectives and practices. London: Routledge/ Falmer.

Piaget, J. and Inhelder, B. (1962). The Psychology of the Child. New York: Basic Books.

Punch, S. (2002). Research with Children: The same or different from research with adults? Childhood 9 (3), 321-341.

Punch, S. (2015). Children as Research Subjects: The Ethical Issues. Bangladesh Journal of Bioethics 6 (1). 6-10.

Rajbhandary, J. Hart, R. \& Khatiwada, C. (1999) The Children's Clubs of Nepal: A Democratic Experiment. Save the Children (Norway) and Save the Children (U.S.) with the Children's Environments Research Group. (Available from www.cergnyc.org).

Reynolds, P. (1991). Dance Civic Cat: Child labour in the Zambezi. London: Zed Books.

Robinson, C. and Kellett, M. (2004). Power. In Fraser, S., Lewis, V., Ding, S., Kellet, M. and Robinson, C. (2004) Doing Research with Children. London: Sage.

Robson, E. (2001). Interviews Worth the Tears?: Exploring Dilemmas in Research with Young Carers in Zimbabwe, in Ethics, Place \& Environment, 4(2) 135-142.

Sapkota, P. and Sharma, J. (1996). Participatory Interactions with Children in Nepal. PLA Notes. 25, 61-64.

Sargeant, J. and Harcourt, D. (2012). Doing Ethical Research with Children. Berkshire, England: Open University Press.

Save the Children (1995). Towards a Children's Agenda: New Challenges for Social Development. London: Save the Children.

Vygotsky, L.S. (1962). Thought and Language. Massachusetts Institute of Technology: Wiley.

West, A., O'Kane, C., Hyder, T. (2008). Diverse childhoods: implications for childcare, protection, participation and research practice. In A. Leira and C. Saraceno (eds.) Childhood: changing contexts - Comparative Social Research. Bingley, Ireland: Elsevier/Emerald. 265-292.

Whitebread, D., Basilio, M., Kuvalja, M. and Verma, M. (2012). The importance of play. Brussels, Belgium: Toys Industries for Europe. Available:

http://www.importanceofplay. eu/IMG/pdf/dr_david_whitebread_-_the_importance_ of_play.pdf. Accessed 5th January 2014.

Young, L. and Barrett, H. (2001). Adapting Visual Methods: Action Research with Kampala Streetchildren. Area, 33: 141-152. 
Key Words: Participation, methods, young children 